\title{
Decision models for sustainable supply chain design and management
}

\author{
Behnam Fahimnia ${ }^{1} \cdot$ Joseph Sarkis $^{2}$. \\ Angappa Gunasekaran ${ }^{3}$ - Reza Farahani ${ }^{4}$
}

Published online: 14 February 2017

(C) Springer Science+Business Media New York 2017

A truly sustainable organization requires ongoing changes in how its supply chain is designed and managed through explicit considerations of economic, environmental, and social performance measures in strategic, tactical, and operational decision making (Brandenburg et al. 2014; Fahimnia et al. 2015a). The development of a sustainable supply chain has remained an 'aspiration' primarily due to the complexities associated with the development of supply chain optimization models that are able to capture and quantify the key social and environmental performance measures, in addition to the traditional economic-oriented measures (Fahimnia et al. 2015c; Rezaee et al. 2017). Recent reviews have shown that theoretical and conceptual studies of sustainable supply chain management have dominated the field, with little attention being given to the development of analytical models and decision tools that incorporate multiple sustainability measures into supply chain design and management decisions (Fahimnia et al. 2015b; Seuring 2013).

This special issue of the Annals of Operations Research includes ten papers that make original contributions to the development of analytical models and decision tools for design and management of sustainable supply chains. While each paper offers clear modeling and methodological contributions, a common aspect of all papers is the use of real data in exploring the real world applications of these modeling efforts. We hope you enjoy reading these papers as much as the guest editors and reviewers of the papers did.

Behnam Fahimnia

behnam.fahimnia@sydney.edu.au

1 Institute of Transport and Logistics Studies, The University of Sydney, Sydney, Australia

2 Foisie School of Business, WPI School of Business, Worcester Polytechnic Institute, MA 01609-2280, USA

3 Charlton College of Business, University of Massachusetts, MA 02747-2300, USA

4 Kingston Business School, Kingston University London, Kingston Hill, UK 


\section{References}

Brandenburg, M., Govindan, K., Sarkis, J., \& Seuring, S. (2014). Quantitative models for sustainable supply chain management: developments and directions. European Journal of Operational Research, 233, 299312.

Fahimnia, B., Sarkis, J., Boland, J., Reisi, M., \& Goh, M. (2015a). Policy insights from a green supply chain optimization model. International Journal of Production Research, 53, 6522-6533.

Fahimnia, B., Sarkis, J., \& Davarzani, H. (2015b). Green supply chain management: a review and bibliometric analysis. International Journal of Production Research, 162, 101-114.

Fahimnia, B., Sarkis, J., \& Eshragh, A. (2015c). A tradeoff model for green supply chain planning: a leannessversus-greenness analysis. OMEGA. An International Journal of Management Science, 54, 173-190.

Rezaee, A., Dehghanian, F., Fahimnia, B., \& Beamon, B. (2017). Green supply chain network design with stochastic demand and carbon price. Annals of Operations Research. doi:10.1007/s10479-015-1936-z6$\mathrm{Z}$.

Seuring, S. (2013). A review of modeling approaches for sustainable supply chain management. Decision Support Systems, 54, 1513-1520. 